\title{
Development of Lateral Flow Immunoassay for Antigen Detection in Human Angiostrongylus cantonensis Infection
}

\author{
Mu-Xin Chen ${ }^{1,2,3, \dagger}$, Jia-Xu Chen ${ }^{1, \dagger}$, Shao-Hong Chen', Da-Na Huang ${ }^{2}$, Lin Ai ${ }^{1,2, *}$, Ren-Li Zhang ${ }^{2, *}$ \\ ${ }^{1}$ National Institute of Parasitic Diseases, Chinese Center for Disease Control and Prevention, WHO Collaborating Center for Tropical Diseases, Key \\ Laboratory of Parasite and Vector Biology, National Health and Family Planning Commission, Shanghai 200025, PR China; ${ }^{2}$ Shenzhen Center for \\ Diseases Control and Prevention, Shenzhen, Guangdong Province 518055, PR China; ${ }^{3}$ Department of Microbiology and Microbial Engineering, \\ School of Life Sciences, Fudan University, Shanghai 200438, PR China
}

\begin{abstract}
Angiostrongyliasis is difficult to be diagnosed for the reason that no ideal method can be used. Serologic tests require specific equipment and are not always available in poverty-stricken zone and are time-consuming. A lateral flow immunoassay (LFIA) may be useful for angiostrongyliasis control. We established a LFIA for the diagnosis of angiostrongyliasis based on 2 monoclonal antibodies (mAbs) against antigens of Angiostrongylus cantonensis adults. The sensitivity and specificity were $91.1 \%$ and $100 \%$ in LFIA, while those of commercial ELISA kit was $97.8 \%$ and $86.3 \%$, respectively. Youden index was 0.91 in LFIA and 0.84 in commercial ELISA kit. LFIA showed detection limit of $1 \mathrm{ng} / \mathrm{ml}$ of $A$. cantonensis ES antigens. This LFIA was simple, rapid, highly sensitive and specific, which opened an alternative approach for the diagnosis of human angiostrongyliasis.
\end{abstract}

Key words: Angiostrongylus cantonensis, lateral flow immunoassay, monoclonal antibody, antigen detection

Angiostrongylus cantonensis is a zoonotic parasite causing eosinophilic meningitis in humans by ingesting infective larvae in snails and slugs of freshwater and terrestrial, paratenic hosts (such as freshwater fish, shrimps, frogs, and crabs) or contaminated vegetables [1-5]. With the increasing income, improved living standards, and the pursuit of exotic and delicate foods, angiostrongyliasis is becoming an important foodborne parasitic zoonosis distributed almost all over the world [6-10]. The diagnosis of human angiostrongyliasis mainly depends on both clinical characters and laboratory tests. Definitive diagnosis is performed by the isolation of larval or juvenile worms in the cerebrospinal fluid (CSF) of infected individuals. However, due to the difficulty of obtaining such material, a definitive diagnosis usually cannot be carried out. Instead, immunological tests are used, because A. cantonensis is seldom found in the limited volume of CSF analyzed [11-13]. The serological tests are the most widely distributed methods for complementary diagnosis of specific antibodies against Angiostrongylus costari-

- Received 21 February 2016, revised 4 May 2016, accepted 7 May 2016.

*Corresponding author (252120016@qq.com; renlizhang@tom.com)

${ }^{\dagger}$ Mu-Xin Chen and Jia-Xu Chen contributed equally to this work.

(c) 2016, Korean Society for Parasitology and Tropical Medicine

This is an Open Access article distributed under the terms of the Creative Commons Attribution Non-Commercial License (http://creativecommons.org/licenses/by-nc/4.0) which permits unrestricted non-commercial use, distribution, and reproduction in any

medium, provided the original work is properly cited. censis, such as the latex agglutination test and ELISA [14-17]. There is no data reported on the sensitivity and specificity of the latex test, and low sensitivity and cross-reaction with other helminthiases are a big problem of ELISA tests [16,18-20]. Nevertheless, the current enzyme immunoassay format is time-consuming because of the need for multiple reagent additions and long-time washing, incubation steps, and is not convenient to be used in large-scale filed investigation and in clinical laboratories.

A more user-friendly, rapid, filtration-based immunogold assay is widely applied. Lateral flow immunoassay (LFIA) is a rapid, single-step immunochromatographic assay that uses colloidal gold as the tracer [21]. In 1990, Beggs [22] first developed the colloidal gold immunochromatography assay for qualitative detection of human chorionic gonadotropin (HCG), and this assay has been widely applied to diagnose many diseases. Its advantages are rapid, simple, specific, and sensitive characteristics. Additionally, this method has also been used to detect bioactive molecules, hormones, and haptens $[23,24]$. With regard to parasite infections, LFIA has been successfully and widely used to detect malaria $[25,26]$. The objective of the present study was therefore to establish the LFIA method, which was based on the monoclonal antibody (mAb) technology, for detecting human angiostrongyliasis. 
LFIA we developed offered a method for specifically, sensitively, and rapidly detecting human angiostrongyliasis.

Ethical clearance for the collection and examination of human sera was obtained from the Ethics Committee of the National Institute of Parasitic Diseases (NIPD), Chinese Center for Disease Control and Prevention (China CDC), China. All animals were handled in strict accordance with good animal practice according to the Animal Ethics Procedures and Guidelines of the People's Republic of China, and the study was approved by the Animal Welfare and Ethics Committee of NIPD, China CDC (permit no: IPD2012-5). Sera of 80 specificpathogen free (SPF) rats and 15 SPF mice infected with A. cantonensis were stored at $-80^{\circ} \mathrm{C}$ until used in our laboratory.

All of those positive sera collected from patients who were confirmed either by "gold standard assays" that was pathologi$\mathrm{cal} /$ parasitological examinations and/or immunological methods (Supplementary Table S1), or by combination of specific clinical symptoms and routine serological methods in accordance with the national criteria for clinical diagnosis of parasitic diseases. A total of 90 sera were obtained from patients with angiostrongyliasis. Among them, 3 patients were confirmed by parasitology (presence of larvae in the cerebrospinal fluid) and 87 ones clinically along with a previous history of eating raw or undercooked food contaminated with parasites, intermediate hosts, or transport hosts of A. cantonensis. The diagnosis was made at Diseases Control and Prevention, Shenzhen, P. R. China in accordance with the national diagnostic criteria of angiostrongyliasis issued by Ministry of Health of $\mathrm{P}$. R. China [27]. In this group, eosinophilia (with at least 7\% of white cell counts in the peripheral blood) and evidence of brain image abnormality were observed. There was also high specificity in ELISA to the whole A. cantonensis antigen $[2,28]$.

All serum samples obtained from Chinese patients infected with Clonorchis sinensis, Schistosoma japonicum, and Ascaris lumbricoides were diagnosed by parasitological examination, or the eggs were detected in feces [29]. Furthermore, there were 30 serum samples from patients infected with Paragonimus westermani confirmed parasitologically with the eggs detected from the sputum or pleural fluid [30]. A total of 20 serum samples of patients infected with cysticercus cellulosae (metacestode of Taenia solium) were collected from Yunnan province, P. R. China. Among them, 12 patients had been confirmed by pathological diagnosis. The others were diagnosed by serological methods (using an ELISA kit produced by Combined Biotech Company, Shenzhen, Guangdong, P. R. China). All these patients presented with the symptoms of dizziness, raised intracranial pressure, or emotional disturbance, and a history of consuming raw pork. Ten patients infected with Echinococcus

Table 1. Functionality of lateral flow immunoassay (LFIA) for human angiostrongyliasis in comparison with a commercial ELISA kit

\begin{tabular}{|c|c|c|c|}
\hline Sera & No. examined & Ag positive (\%) by LFIA & Ab positive (\%) by ELISA \\
\hline Rats infected with $A$. cantonensis & 80 & 100 & nd \\
\hline Normal rats & 50 & 0 & nd \\
\hline Mice infected with $A$. cantonensis & 15 & 100 & nd \\
\hline Normal mice & 10 & 0 & nd \\
\hline Patients of $A$. cantonensis & 90 & 91.1 & 97.8 \\
\hline Patients of $C$. sinensis & 50 & 0 & 12.0 \\
\hline Patients of S. japonicum & 30 & 0 & 16.7 \\
\hline Patients of $P$. westermani & 30 & 0 & 10.0 \\
\hline Patients of $A$. lumbricoides & 30 & 0 & 43.3 \\
\hline Patients of C. cellulosae & 20 & 0 & 20.0 \\
\hline Patients of $E$. granulosus & 10 & 0 & 10.0 \\
\hline Patients of $T$. gondii & 10 & 0 & 10.0 \\
\hline Patients of $T$. spiralis & 10 & 0 & 30.0 \\
\hline Patients of Spirometra plerocercoids & 10 & 0 & 20.0 \\
\hline Healthy adults & 100 & 0 & 0 \\
\hline Sensitivity (\%) [95\% Cl] & & 91.1 [85.2-97.0] & 97.8 [94.8-100.0] \\
\hline Specificity (\%) [95\% Cl] & & 100.0 & 86.3 [82.4-90.2] \\
\hline PPV (\%) [95\% Cl] & & 100.0 & $68.2[60.2-76.2]$ \\
\hline NPV (\%) [95\% Cl] & & 97.4 [95.6-99.2] & 99.2 [98.1-100.0] \\
\hline Youden's index & & 0.91 & 0.84 \\
\hline
\end{tabular}

nd, not determined; $\mathrm{Cl}$, confidence interval. 
granulosus larvae were confirmed by parasitology after surgery, while the patients infected with Toxoplasma gondii were confirmed serologically by using ELISA kits (Combined Biotech Company). Serum samples of 10 trichinellosis patients were collected from Yunnan province, P. R. China, of which 5 cases confirmed pathologically or by finding Trichinella spiralis larvae in muscle sections. The remaining 5 cases were diagnosed serologically by using an ELISA kit (Combined Biotech Company). Ten serum samples were collected from patients infected with Spirometra spp., which were confirmed by surgery (larvae of subcutaneous Spirometra spp.) (Table 1; Supplementary Table S1). Sera of healthy adult people were collected from the serum bank stored at $-80^{\circ} \mathrm{C}$ in Diseases Control and Prevention, Shenzhen, P. R. China (Table 1). A. cantonensis Shenzhen strain has been maintained through SPF rats in our laboratory. Rats were orally infected with the third stage larvae (L3) from infected Achatina fulica snail, and from the rat lungs, adult worms were harvested on the day 33 post-infection. Excretorysecretory (ES) products of $A$. cantonensis worms were obtained by incubating the adult worms in physiologic saline for 3 days at room temperature (RT).

The mAbs (12D5C12, 21B7B11) against ES antigens of $A$. cantonensis were previously produced in our laboratory [31]. The mAb 12D5C12 is IgG1 and mAb 21B7B11 is IgM. These mAbs recognized independently epitopes on an ES antigen (98 $\mathrm{kDa}$ ) of A. cantonensis adult worms. These mAbs can react with eggs, first-stage larvae, and the adults of A. cantonensis, suggesting that different developmental stages of A. cantonensis secrete common antigens.

Immunochromatographic strip was composed of 4 parts, including the sample pad, conjugate pad, immobilized nitro- cellulose membrane, and absorbent pad. The sample pad influencing migration of the gold nanoparticle-antibody conjugate was treated with $50 \mathrm{mmol} / \mathrm{L}$ borate buffer ( $\mathrm{pH} 7.4$ ) containing $1 \%$ BSA, $0.5 \%$ Tween-20, and $0.05 \%$ sodium azide. Gold nanoparticles were coated with mAb 21B7B11 by a method with modifications [32,33]. The coated gold particles were added to the glass-fiber conjugate pad and dried at $37^{\circ} \mathrm{C}$ for $2 \mathrm{hr}$. The test line (T) was coated with $2.0 \mathrm{mg} / \mathrm{ml} \mathrm{mAb}$ (12D5C12) and the control line (C) with $0.8 \mathrm{mg} / \mathrm{ml}$ goat antimouse IgM. Those pretreated 4 parts were stuck on a polyvinyl chloride (PVC) plate, cut into $3 \mathrm{~mm}$ wide strips and stored dry at $4^{\circ} \mathrm{C}$ until used. All sera from patients infected with parasites or healthy individuals were examined along operation manual of the commercial ELISA kit for specific IgG antibody of $A$. cantonensiss. A schematic representation of the immunochromatographic test device was shown in Fig. 1. All sera from patients infected with different parasites and healthy individuals were examined by GICA. Briefly, $20 \mu \mathrm{l}$ serum was dropped into the sample pad and incubated at $37^{\circ} \mathrm{C}$ for $5-10 \mathrm{~min}$.

In the detection zone, the goat anti-mouse IgM and $\mathrm{mAb}$ (12D5C12) were separately stripped onto $\mathrm{C}$ or $\mathrm{T}$ line, and the goat anti-mouse IgM were reacted with the $\mathrm{mAb}$ (21B7B11)coated colloidal gold particles in the control region for the reaction, while mAb (12D5C12) were reacted with the A. cantonensis antigen bound $\mathrm{mAb}$ (21B7B11)-coated colloidal gold particles in the test region. A positive result can be judged by 2 red lines in $\mathrm{C}$ and $\mathrm{T}$ regions, and a negative result by only a single line in $\mathrm{C}$ region. The darker the color of the test line is, the higher the concentration of the antigen in the sample is. The test was invalid if there was no line in both regions or only 1 line in $\mathrm{T}$ region. The ES products of $A$. cantonensis adult

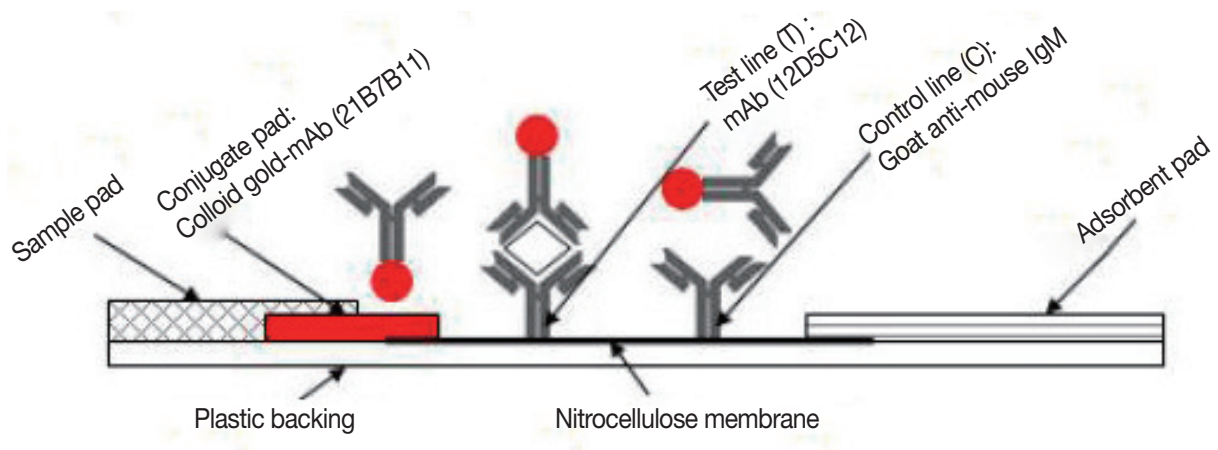

Flow through

Fig. 1. The schematic representation of the immunochromatographic test device. 


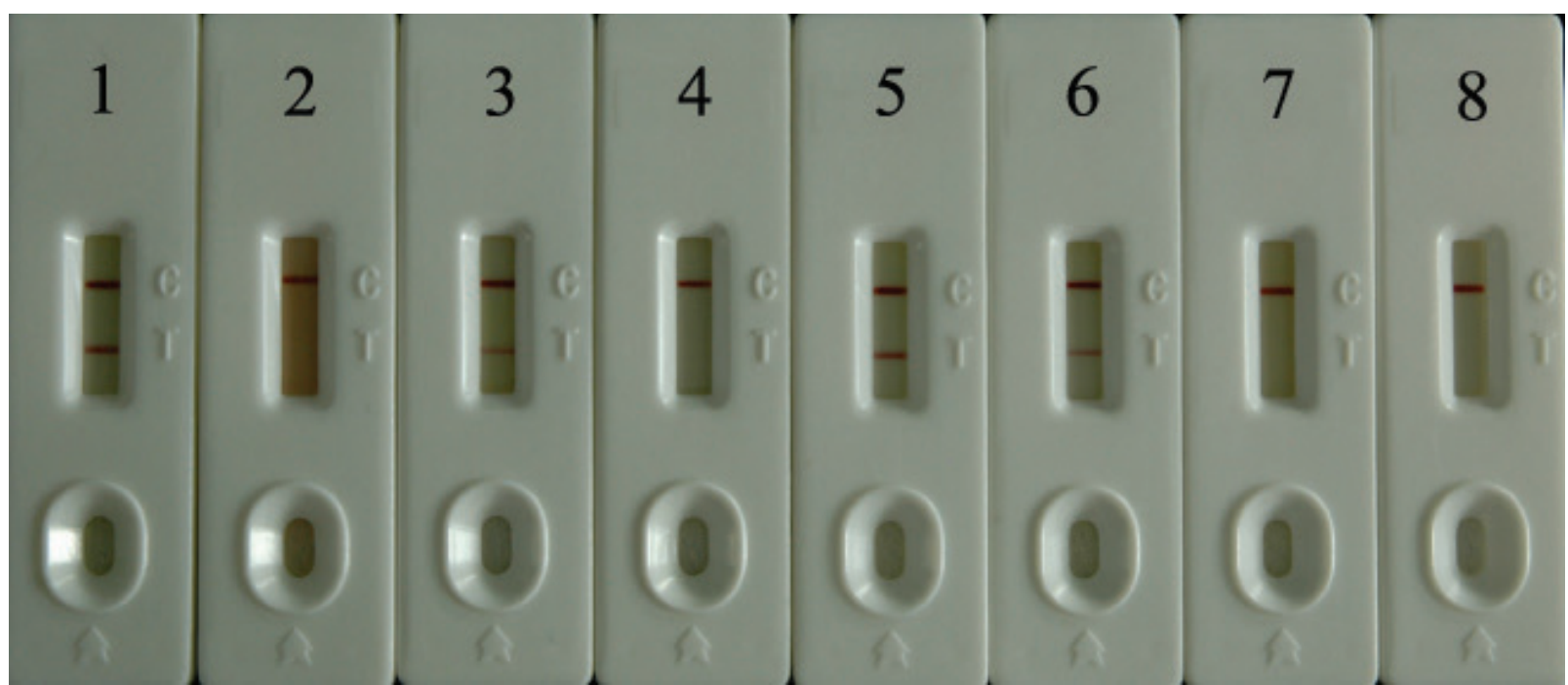

Fig. 2. Reactivity of LFIA to rat, mice, and human sera. 1-2, Sera of SD rat infected with $A$. cantonensis and normal rat; 3-4, Sera of SPF BALB/c mouse infected with $A$. cantonensis and normal one; 5-6, Sera of 2 patients infected with $A$. cantonensis; 7 , Serum of a healthy adult; 8, Serum of a patient infected with $A$. lumbricoides.

worms were 2-fold diluted to $0.5-8 \mathrm{ng} / \mathrm{ml}$ with a pooled serum of health adults. The different concentrations of $A$. cantonensis ES products were detected using the immunoassay strips described above. All data were processed and analyzed with Microsoft Office Excel 2007. The sensitivity, specificity, positive predictive value (PPV), and negative predictive value (NPV) were calculated relative to the 'gold' standard parasitological or serological results that correlated to each serum sample (Table S1). The $95 \%$ confidence intervals (95\% CI) were determined as described previously [30]. Youden index summarizes the discriminatory accuracy of a diagnostic test and provides a ready-to-use optimal cut-point for the purpose of future diagnosis. Youden index was defined [34] as J $(\mathrm{t})=$ sensitivity + specificity-1. Practically, this definition renders a maximum value of 1 when a diagnostic test provides a perfect separation between 2 populations and a minimum of zero when it classifies no better than chance. It was used to assess the ability of the test to discriminate true positives and true negatives.

The specificity and sensitivity of LFIA was $91.1 \%$ (95\% CI: 85.2-97.0\%) and 100\% (95\% CI: 100.0\%), respectively (Table 1; Fig. 2). Youden index of LFIA was 0.91 (Table 1). The specificity and sensitivity of the commercial ELISA kit was $97.8 \%$ and $86.3 \%$ (Table 1), respectively. Youden index of the commercial ELISA kit was 0.84 (Table 1). The assay was completed in less than $10 \mathrm{~min}$ (5-10 min). The detection limit of LFIA was $1 \mathrm{ng} / \mathrm{ml}$ of A. cantonensis ES products. The red color intensity of the test line was proportional to the antigen concentra- tion in the range of $0.5-8 \mathrm{ng} / \mathrm{ml}$. Sera of health adults showed no band in the Tline (Supplementary Fig. 1S).

Most of the specific methods for angiostrongyliasis diagnosis used at present are not satisfied for the shortages of insufficient sensitivity, specificity, and reproducibility $[16,20,35]$. Serological surveillance will be useful in determining the infection status, and it plays an important role in the control of this parasitic disease in humans. Compared with other methods for diagnosis of A. cantonensis infection, such as the latex test and ELISA test, Gan et al. [36] generated an initial non-enzymatic, dot immunogold filtration assay (DIGFA) with crude antigen preparation which was used to detect specific IgG antibodies against $A$. cantonensis in infected patients and was found to have a diagnostic sensitivity of $91 \%$ and specificity of 98\% for human angiostrongyliasis [36]. However, crude antigens may lead to cross reactions with other nematode infections. Subsequently, a modified rapid dot-immunogold test using purified $31 \mathrm{kDa}$ antigen of $A$. cantonensis to enhance test sensitivity has performed well on clinical samples at Siriraj Hospital. The test is rapid, easy to perform, and needs no special equipment [37]. However, $31 \mathrm{kDa}$ antigen was mainly used for antibody detection, which was not able to distinguish past infection or current infection. This phenomenon was because antibodies will persist in the human body after treatment. Using monoclonal antibodies to detect $A$. cantonensis circulating antigen, it can better distinguish past infection or current infection, as well as can be applied to better assess- 
ment of therapeutic effects.

Currently, the LFIA assay system demonstrated in this study can give a confident analytical performance and can be constructed in the laboratory by preparing 2 major components; one was the detection $\mathrm{mAb}$ labelled with a signal generator, such as $\mathrm{mAb} 21 \mathrm{~B} 7 \mathrm{~B} 11$, and the other was the capture $\mathrm{mAb}$ which was immobilized on the surfaces of membrane strip, such as mAb 12D5C12. The method is more rapid and easier to perform than the traditional ELISA assay. The test utilizing A. cantonensis mAbs is reliable and reproducible for specific immunodiagnosis of human infections with $A$. cantonensis. Thus, it can be applied as an additional routine test for clinical diagnostic support and large-scale seroepidemiological studies in endemic communities to evaluate its usefulness under field conditions. Moreover, the test required no instrumentations, and the results can be obtained in only 5-10 min. The constructed kits have some benefits, too, such as user friendly format, very short time to get test results, long shelf life at RT, and relatively inexpensive for preparation.

In conclusion, the present study established a LFIA for the detection of A. cantonensis circulating antigen in sera of patients and animals. The established kit and LFIA methods should provide a useful detecting approach for clinical diagnosis and assessment of chemical treatment effects.

\section{ACKNOWLEDGMENTS}

This work is supported in part by the Program for National S\&T Major Program (grant no. 2012ZX10004-220), the Chinese Special Program for Scientific Research of Public Health (no. 201502021), the Natural Science Foundation of Guangdong Province (grant no. 81518020030002), Shenzhen Municipal Bureau of Science, Technology and Information (grant no. 2007079), and Parasitic and Tropical Diseases Resource Center Project of National Science and Technology Basic Conditions Platform Program.

\section{CONFLICT OF INTEREST}

We have no conflict of interest related to this study.

\section{REFERENCES}

1. Brown FM, Mohareb EW, Yousif F, Sultan Y, Girgis NI. Angiostrongylus eosinophilic meningitis in Egypt. Lancet 1996; 348:
964-965.

2. Slom T], Cortese MM, Gerber SI, Jones RC, Holtz TH, Lopez AS, Zambrano CH, Sufit RL, Sakolvaree Y, Chaicumpa W, Herwaldt BL, Johnson S. An outbreak of eosinophilic meningitis caused by Angiostrongylus cantonensis in travelers returning from the Caribbean. N Engl J Med 2002; 346: 668-675.

3. Wang QP, Lai DH, Zhu XQ, Chen XG, Lun ZR. Human angiostrongyliasis. Lancet Infect Dis 2008; 8: 621-630.

4. Zhang RL, Chen MX, Gao ST, Geng YJ, Huang DN, Liu JP, Wu YL, Zhu XQ. Enzootic angiostrongyliasis in Shenzhen, China. Emerg Infect Dis 2008; 14: 1955-1956.

5. Eamsobhana P, Yong HS. Immunological diagnosis of human angiostrongyliasis due to Angiostrongylus cantonensis (Nematoda: Angiostrongylidae). Int J Infect Dis 2009; 13: 425-431.

6. Zhou P, Chen N, Zhang RL, Lin RQ, Zhu XQ. Food-borne parasitic zoonoses in China: perspective for control. Trends Parasitol 2008; 24: 190-196.

7. Dorta-Contreras AJ, Magraner-Tarrau ME, Sánchez-Zulueta E. Angiostrongyliasis in the Americas. Emerg Infect Dis 2009; 15: 991.

8. Lv S, Zhang Y, Liu HX, Hu L, Yang K, Steinmann P, Chen Z, Wang LY, Utzinger J, Zhou XN. Invasive snails and an emerging infectious disease: results from the first national survey on Angiostrongylus cantonensis in China. PLoS Negl Trop Dis 2009; 3: e368.

9. De NV, Duyet le V, Chai JY. A case of ocular angiostrongyliasis with molecular identification of the species in Vietnam. Korean J Parasitol 2015; 53: 713-717.

10. Sawanyawisuth $K$, Chindaprasirt J, Senthong V, Limpawattana $P$, Auvichayapat N, Tassniyom S, Chotmongkol V, Maleewong W, Intapan PM. Clinical manifestations of Eosinophilic meningitis due to infection with Angiostrongylus cantonensis in children. Korean J Parasitol 2013; 51: 735-738.

11. Podwall D, Gupta R, Furuya EY, Sevigny J, Resor SR. Angiostrongylus cantonensis meningitis presenting with facial nerve palsy. J Neurol 2004; 251: 1280-1281.

12. Lv S, Zhang Y, Steinmann P, Zhou XN. Emerging angiostrongyliasis in Mainland China. Emerg Infect Dis 2008; 14: 161-164.

13. Wang J, Qi H, Diao Z, Zheng X, Li X, Ma S, Ji A, Yin C. An outbreak of angiostrongyliasis cantonensis in Beijing. J Parasitol 2010; 96: 377-381.

14. Uga S, Ono K, Kataoka N, Hasan H. Seroepidemiology of five major zoonotic parasite infections in inhabitants of Sidoarjo, East Java, Indonesia. Southeast Asian J Trop Med Public Health 1996; 27: 556-561.

15. Geiger SM, Abrahams-Sandi E, Soboslay PT, Hoffmann WH, Pfaff AW, Graeff-Teixeira C, Schulz-Key H. Cellular immune responses and cytokine production in $\mathrm{BALB} / \mathrm{c}$ and $\mathrm{C} 57 \mathrm{BL} / 6$ mice during the acute phase of Angiostrongylus costaricensis infection. Acta Trop 2001; 80: 59-68.

16. Tomanakan K, Srisurach N, Sae-tung S, Pengpinich C. Detection of circulating antibody of Parastrongylus cantonensis in sera with eosinophilic meningitis by dot-blot ELISA. J Med Assoc Thai 
2008; 91: 1082-1086.

17. Chen MX, Wang K, Ai L, Yan WH, Peng L, Zhang RL. Development of a double antibody sandwich ELISA assay for the diagnosis of angiostrongyliasis. J Parasitol 2011; 97: 721-724.

18. Eamsobhana P, Mak JW, Yong HS. Detection of circulating antigens of Parastrongylus cantonensis in human sera by sandwich ELISA with specific monoclonal antibody. Southeast Asian J Trop Med Public Health 1995; 26: 712-715.

19. Eamsobhana P, Yong HS, Mak JW, Wattanakulpanich D. Detection of circulating antigens of Parastrongylus cantonensis in human sera by dot-blot ELISA and sandwich ELISA using monoclonal antibody. Southeast Asian J Trop Med Public Health 1997; 28: 624-628.

20. Liang SH, Huang HC, Pan CW, Tan F. Detection of Angiostrongylus cantonensis circulating antigen by monoclonal antibodies. Zhonghua Yi Xue Za Zhi 2005; 85: 3057-3061. (in Chinese)

21. Rouf MA, Rahman ME, Islam MN, Ferdous NN, Hossain MA. Sensitivity, specificity and predictive values of immunochromatographic strip test in diagnosis of childhood kala-azar. Mymensingh Med J 2009; 18: S1-5.

22. Beggs M, Novotny M, Sampedro S, Devore J, Gordon J, Osikowicz G. A self-performing chromatographic immunoassay for the qualitative determination of human chorionic-gonadotropin (hcg) in urine and serum. Clin Chem 1990; 36: 1084-1085.

23. Heeschen C, Goldmann BU, Moeller RH, Hamm CW. Analytical performance and clinical application of a new rapid bedside assay for the detection of serum cardiac troponin I. Clin Chem 1998; 44: 1925-1930.

24. Watanabe T, Ohkubo Y, Matsuoka H, Kimura H, Sakai Y, Ohkaru Y, Tanaka T, Kitaura Y. Development of a simple whole blood panel test for detection of human heart-type fatty acid-binding protein. Clin Biochem 2001; 34: 257-263.

25. Wang JY, Wang JJ, Shi F, Xu X, Yang YT, Gao CH, Zheng X, Ge J, Tang LH. Field evaluation of gold-immunochromatographic assay for diagnosis of vivax malaria. Zhongguo Ji Sheng Chong Xue Yu Ji Sheng Chong Bing Za Zhi 2009; 27: 500-502 (in Chinese).

26. Wu YS, Lei LM, Li M. Evaluation of a parasite lactate dehydrogenase-based colloid gold-immunochromatography assay for diagnosis of Plasmodium falciparum. Di Yi Jun Yi Da Xue Xue Bao
2005; 25: 761-765 (in Chinese).

27. Lv S, Zhang Y, Chen SR, Wang LB, Fang W, Chen F, Jiang JY, Li YL, Du ZW, Zhou XN. Human angiostrongyliasis outbreak in Dali, China. PLoS Negl Trop Dis 2009; 3: e520.

28. Chau TT, Thwaites GE, Chuong LV, Sinh DX, Farrar JJ. Headache and confusion: the dangers of a raw snail supper. Lancet 2003; 361: 1866 .

29. Shrivastava B. Medical Parasitology. LAP Lambert Academic Publishing, 2011.

30. Chen JX, Chen MX, Ai L, Chen JH, Chen SH, Zhang YN, Cai YC, Zhu XQ, Zhou XN. A protein microarray for the rapid screening of patients suspected of infection with various food-borne helminthiases. PLoS Negl Trop Dis 2012; 6: e1899.

31. Chen MX, Zhang RL, Chen JX, Chen SH, Li XH, Gao ST, Geng YJ, Huang DN, Ai L, Xu MJ, Zhu XQ. Generation and characterization of monoclonal antibodies against excretory/secretory antigens of Angiostrongylus cantonensis. Hybridoma (Larchmt) 2010; 29: 447-452.

32. Jennes L, Conn PM, Stumff WE. Synthesis and use of colloidal gold coupled receptor ligands. Methods Enzymol 1986; 124: 3647.

33. Oliver C. Conjugation of colloidal gold to proteins. Methods Mol Biol 1994; 34: 303-307.

34. Youden WJ. Index for rating diagnostic tests. Cancer 1950; 3: $32-$ 35.

35. Wilkins PP, Qvarnstrom Y, Whelen AC, Saucier C, da Silva AJ, Eamsobhana P. The current status of laboratory diagnosis of $\mathrm{An}$ giostrongylus cantonensis infections in humans using serologic and molecular methods. Hawaii J Med Public Health 2013; 72: 55-57.

36. Gan XX, Wang Y, Guo JX, Yang FZ, Zhang LL, Eamsobhana P. Rapid detection of specific IgG antibody for Angiostrongylus cantonensis by dot immunogold filtration assay. Chin J Zoonoses 2007; 23: 345-347 (in Chinese).

37. Eamsobhana P, Gan XX, Ma A, Wang Y, Wanachiwanawin D, Yong HS. Dot immunogold filtration assay (DIGFA) for the rapid detection of specific antibodies against the rat lungworm Angiostrongylus cantonensis (Nematoda: Metastrongyloidea) using purified 31-kDa antigen. J Helminthol 2014; 88: 396-401. 
Chen et al:: Lateral flow immunoassay for Angiostrongylus cantonensis infection

Table S1. The diagnoses of 290 patients by the parasitological or serological method

\begin{tabular}{lccc}
\hline Patients & No. of patients diagnosed by parasitology & No. of patients diagnosed by serology & Total \\
\hline Patients of Angiostrongylus cantonensis & 3 & 87 & 0 \\
Patients of Clonorchis sinensis & 50 & 0 & 90 \\
Patients of Schistosoma japonicum & 30 & 0 & 30 \\
Patients of Paragonimus westermani & 30 & 0 & 30 \\
Patients of Ascaris lumbricoides & 30 & 8 & 30 \\
Patients of Cysticercus (cellulosae) & 12 & 0 & 20 \\
Patients of Echinococcus granulosus & 10 & 10 & 10 \\
Patients of Toxoplasma gondii & 0 & 5 & 10 \\
Patients of Trchinella spiralis & 5 & 0 & 10 \\
Patients of Spirometra plerocercoids & 10 & 10 & 10 \\
\hline
\end{tabular}




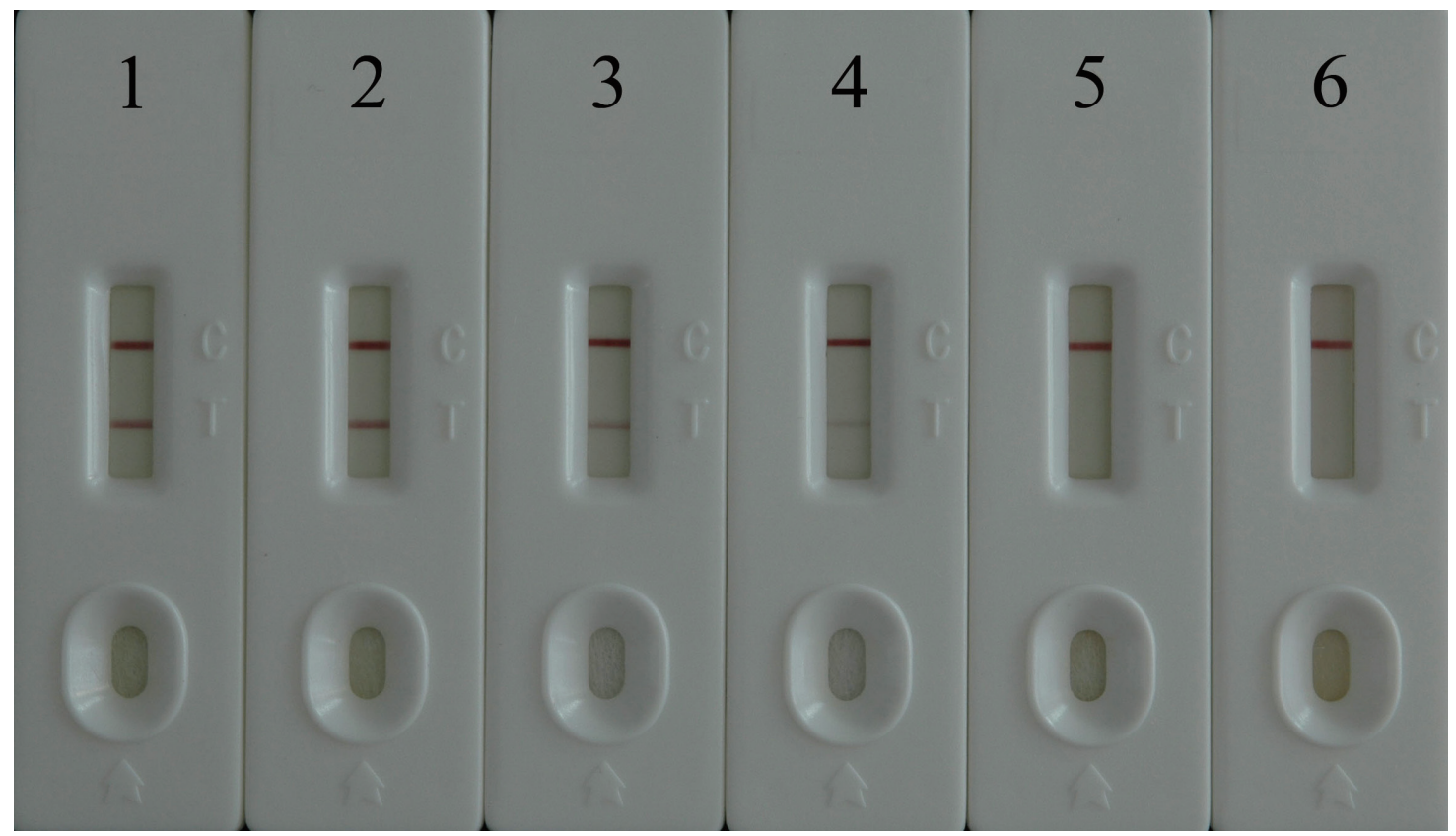

Fig. 1S. Immunochromatographic detection of $A$. cantonensis. $1-5,8 \mathrm{ng} / \mathrm{ml}, 4 \mathrm{ng} / \mathrm{ml}, 2 \mathrm{ng} / \mathrm{ml}, 1 \mathrm{ng} / \mathrm{ml}$, and $0.5 \mathrm{ng} / \mathrm{ml}$ of $A$. cantonensis ES products; 6 , serum of a healthy adult. 